\title{
High-Speed Flywheel and Motor Drive Operation for Energy Recovery in a Mobile Gantry Crane
}

\author{
M. M. Flynn \\ Center for Electromechanics \\ University of Texas \\ 1 University Station, R7000 \\ Austin, TX 78712
}

\author{
P. McMullen \\ VYCON, Inc. \\ 12880 Moore Street \\ Cerritos, CA 90703
}

\author{
O. Solis \\ VYCON, Inc. \\ 12880 Moore Street \\ Cerritos, CA 90703
}

\begin{abstract}
This paper describes the results of experimental testing using a high-speed permanent magnet synchronous machine and its motor drive designed to recover potential energy in mobile gantry crane applications. Rubber-Tired Gantry (RTG) cranes are commonly used in shipping ports around the world to move containers massing up to $\mathbf{4 0}$ metric tons. These cranes are mobile and derive their electrical power requirements for the hoist motor from a diesel engine and generator set rather than from the utility system. Because these cranes are independent of the utility system, energy regenerated via the hoist motor as a container is lowered to the ground is typically wasted as heat in dissipator resistors. This paper details the operation and experimental results of a novel long-life flywheel motor and its drive system which can capture the regenerated energy and provide it for subsequent container lifts. Such a flywheel system has proven to significantly reduce fuel usage and diesel engine emissions.
\end{abstract}

\section{INTRODUCTION}

Large coastal shipping ports operate thousands of diesel engines within ships, trains, trucks, and cranes. While these engines are the workhorse of the industry, their exhaust is a known pollutant that can cause cancer and other diseases. Around the vicinity of the ports of Los Angeles and Long Beach California in particular, diesel exhaust is associated with $70 \%$ of pollution related health problems; moreover, diseases from port pollution are responsible for hundreds of deaths annually in the area [1]. Aware of the problem, these two ports - the busiest in the U.S. - plan to reduce diesel emissions by $50 \%$ over the next 5 years.

Container cranes, such as the rubber-tired gantry (RTG) crane shown in Fig. 1, are major contributors of port-based diesel emissions. These cranes employ conventional power trains consisting of a diesel engine coupled to an alternator which provides electrical power for a set of hoist, trolley, and gantry motors. The diesel engine prime mover allows an RTG crane to be unencumbered by a utility mains connection as it moves about the shipyard.

When a shipping container is lifted by a conventional RTG crane, the diesel engine provides the energy demanded by the hoist motor. When the container is lowered, the container's potential energy is converted by the hoist motor into electrical form, but the conventional drive system has no means to store this regenerated energy. Consequently, this energy is typically dissipated as heat in resistor banks resulting in a reduced

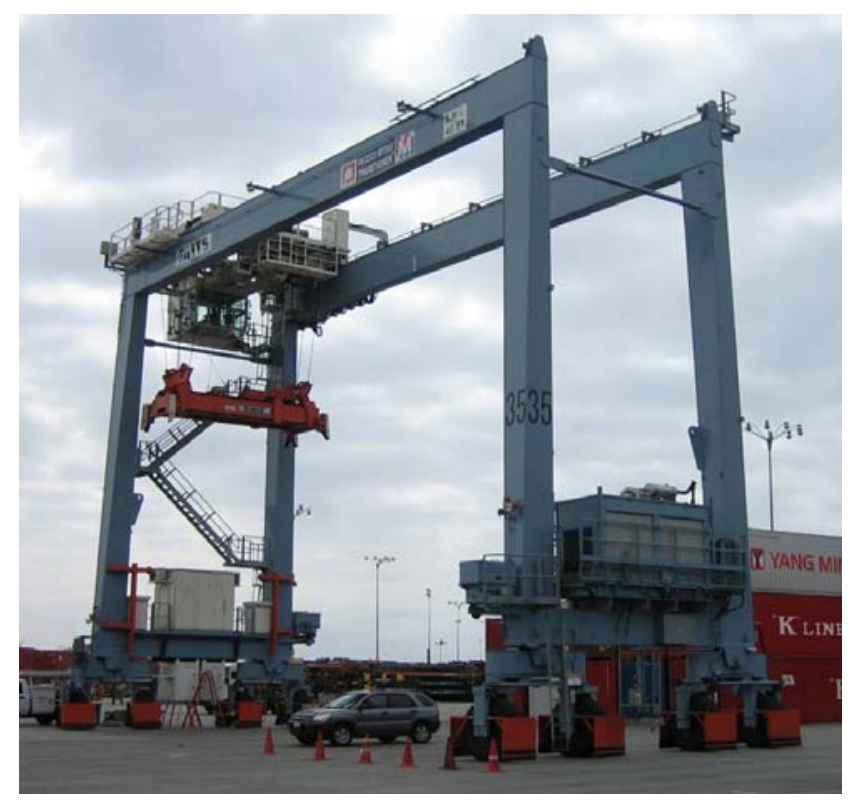

Figure 1. Rubber-tired gantry crane

overall system efficiency and increased fuel consumption and emissions.

This paper describes the results of experimental testing during which the conventional power train of an RTG crane was converted to a hybrid version using a pair of high-speed flywheels for energy storage. High-speed flywheels are ideal energy storage devices for use with RTG cranes as they are able to both source and absorb large amounts of power at the high cycle rates demanded by the hoist motor. They have been used in other demanding high-cycle environments when long life is required with much success [2,3]. This paper will provide: 1) an overview of an RTG crane, 2) its electrical system performance when lifting and lowering loads without flywheels, 3) an overview of the flywheel and its associated motor drive, and 4) the improvement in the operation of the crane with flywheels employed.

\section{CONVENTIONAL RTG CRANE OVERVIEW}

\section{A. Mechanical}

RTG cranes such as the one shown in Fig. 1 are known as 1over-4 RTG cranes since they are able to raise a shipping container above a stack of 4 containers high. The crane grabs 
hold of a container with a device called a spreader. The spreader has a mass of $10 \mathrm{t}$; the crane can lift a maximum shipping container mass of $40.6 \mathrm{t}$ yielding a total lift load of $50.6 \mathrm{t}$.

Using hoist, trolley, and gantry motors, RTG cranes can move containers in three degrees of freedom. The hoist motor is used to raise and lower the container, trolley motors move the container from one side of the crane to the other, and gantry motors are used to reposition the entire crane. This paper focuses on testing conducted with the hoist motor only, since the trolley and gantry motors afford lesser regeneration opportunities.

\section{B. Electrical}

The simplified power train for the crane tested is shown in Fig. 2. The $455 \mathrm{~kW}$ rated diesel engine turns a $500 \mathrm{kVA}, 460$ $\mathrm{V}_{\mathrm{LL}, \mathrm{rms}}$, 3-phase alternator. The output of the alternator is connected to two independent hoist motor drives, each of which powers an isolated 3-phase winding in the hoist motor. Each motor drive connects to the alternator via a 3-phase, fullbridge, passive diode rectifier producing a nominal dc bus voltage of $650 \mathrm{~V}$. The maximum hoist motor power (measured at the dc bus) is limited by the motor drives to approximately $300 \mathrm{~kW}$ total (150 kW per motor drive).

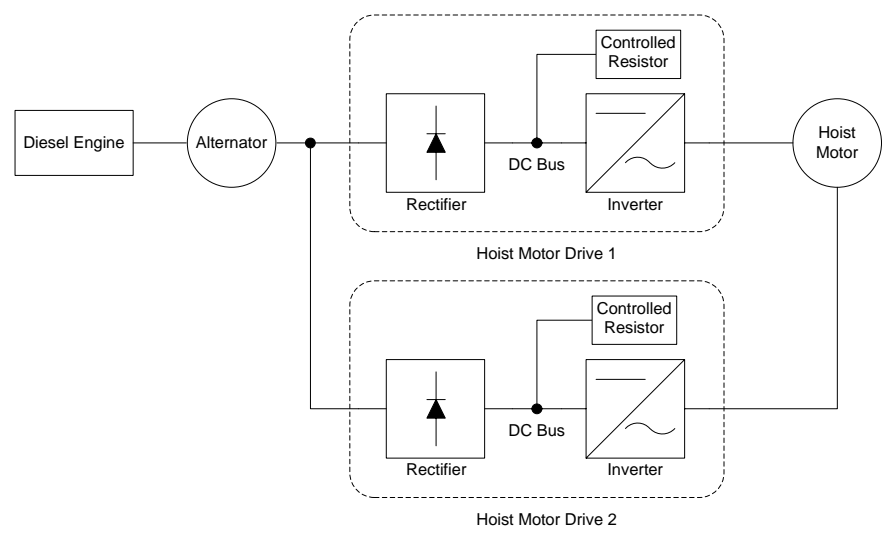

Figure 2. RTG crane hoist motor drive

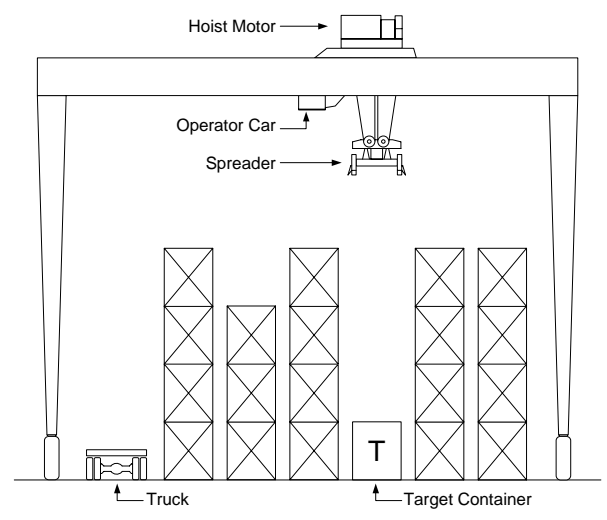

(a) Target container to be acquired with spreader

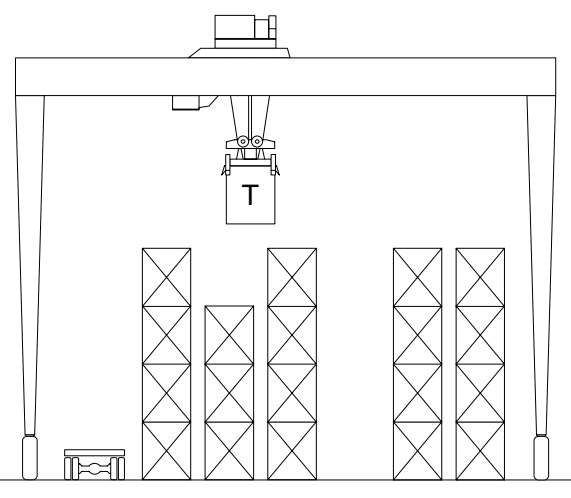

(b) Trolley container to awaiting truck

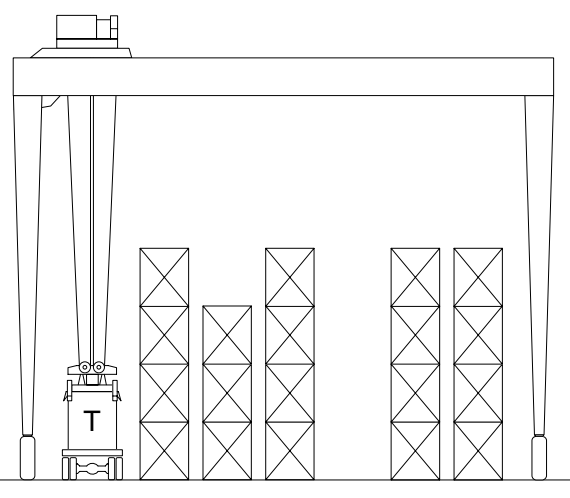

(c) Lower container onto truck and release spreader
During a regeneration event, (i.e. when a container is lowered), the voltage at each dc bus rises significantly commensurate with limited dc bus capacitance. When the voltage on a particular bus equals $730 \mathrm{~V}$, the respective chopper controlled resistor bank is activated to dissipate the regenerated energy. The chopper operates at $100 \%$ duty cycle when the dc bus voltage is above $750 \mathrm{~V}$.

\section{Crane Testing Method}

During operation at the port, crane operators attempt to maintain a pace of moving one container per minute. A typical operating scenario consists of the crane loading containers onto awaiting trucks as shown in Fig. 3. In such a case the empty spreader is lowered into a stack of containers that can be anywhere from 1 to 4 containers high. The target container is acquired and lifted out of the stack. The crane trolleys the container to a position above the truck and then lowers the container onto the truck. The cycle is completed when the empty spreader is raised away from the truck and is then trolleyed back to the container stack.

In the above scenario the empty spreader is raised and lowered once, likewise the combined spreader and container load is raised and lowered once. There are also two trolley operations, one with an empty spreader and one with a combined spreader and container load. From these observations, a testing method was devised that simulates the typical operating scenario and allows for evaluation of the crane's fuel consumption and emissions output both with and without the flywheel energy storage. The test method consists of raising and lowering the empty spreader once a minute for 30 minutes followed by raising and lowering a combined spreader and container load once a minute for 30 minutes. Thus at the end of a standard one hour test, 60 lifts are performed. The trolley events were neglected since energy consumed and regenerated during this time is small compared to that of the hoist motor. The test method is summarized in Table I.

Figure 3. Typical crane operating scenario 
TABLE I

Crane Operations Performed DURING StANDARd One HOUR Fuel CONSUMPTION AND EMISSIONS TEST

\begin{tabular}{ccc} 
& Raise & Lower \\
\hline $\begin{array}{c}\text { Empty spreader operations (cycles) } \\
\begin{array}{c}\text { Combined spreader and container } \\
\text { load operations (cycles) }\end{array}\end{array}$ & 30 & 30
\end{tabular}

In practice, the target container for a given move can be located at a variable height within the four container tall stack. Maximum fuel consumption and emissions output occurs when the target container is located on ground level between full-height container stacks as shown in Fig. 3. These worst case conditions were simulated during testing by raising and lowering the hoist a distance equal to the height of four containers which is approximately $10.6 \mathrm{~m}$

According to port authorities, the typical shipping container has a mass of about $15 \mathrm{t}$. Thus, a container with a similar mass of $15.3 \mathrm{t}$ was selected for use during testing. Throughout the testing, fuel consumption and emissions data were measured. Additionally, electrical system performance was recorded at the dc bus of each hoist motor drive; these locations correspond to the connection points for the flywheel energy storage system described below.

\section{CRANE Operation WITHOUT FLYWHEELS}

\section{A. Lifting Event}

During the first phase of testing, baseline fuel consumption and emissions output from the diesel engine were determined. The crane was operated according to the one hour test described above without the flywheel energy storage. Figs. 4 and 5 show the dc bus power supplied to each hoist motor drive during an empty spreader lift and $15.3 \mathrm{t}$ container lift respectively. During the time the hoist power is ramping towards its peak, the hoist is accelerating; once the desired lifting speed has been achieved, the hoist power demand is reduced and the load is lifted at constant speed with constant power.

At the beginning and end of the lifts, short duration power fluctuations can be observed. The fluctuations, while not desirable, are the signature of the human operator at the controls of the crane and reflect one's personal style of manipulating the joystick controls. Additionally, it is noted that the two motor drives do not supply exactly the same power. For instance, during the time the load is lifted under constant power, drive 1 was recorded in Figs. 4 and 5 as supplying $59.5 \mathrm{~kW}$ and $131 \mathrm{~kW}$ respectively. Similarly, drive 2 supplies $54 \mathrm{~kW}$ and $119 \mathrm{~kW}$ respectively. The mismatch in either case is the same; specifically, drive 1 supplies $10 \%$ more power than drive 2 . The variance can be attributed to motor drive controller settings and tolerances as well as slight mismatches between the two motor windings. Neither of the above two anomalies is a cause for concern during the fuel consumption and emissions testing however, since the hoist motor drives perform similarly with or without the flywheels and the same human operator is used for both portions of the test.

Fig. 6 shows the dc bus voltages and dc rectifier currents for the hoist motor drives during a container lift. The voltages sag

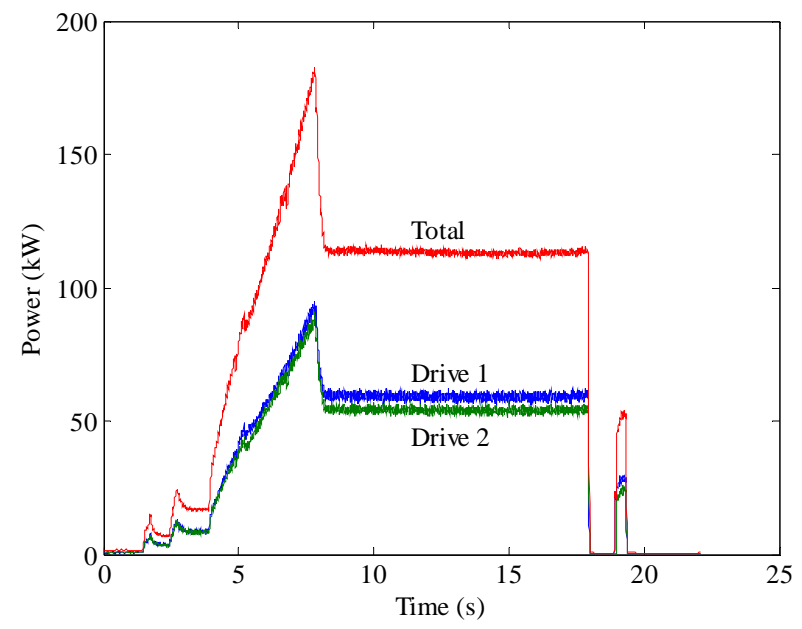

Figure 4. Dc bus hoist motor drive power during spreader lift

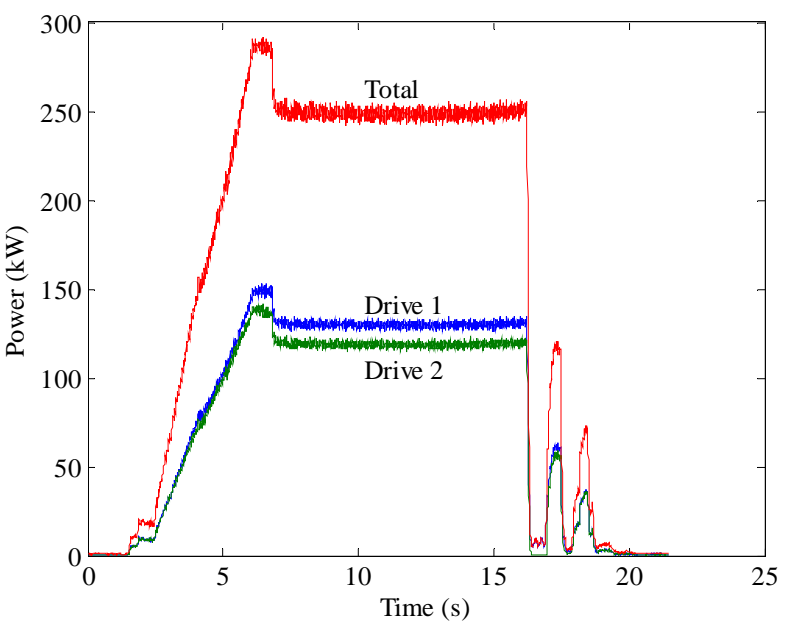

Figure 5. Dc bus hoist motor drive power during container lift

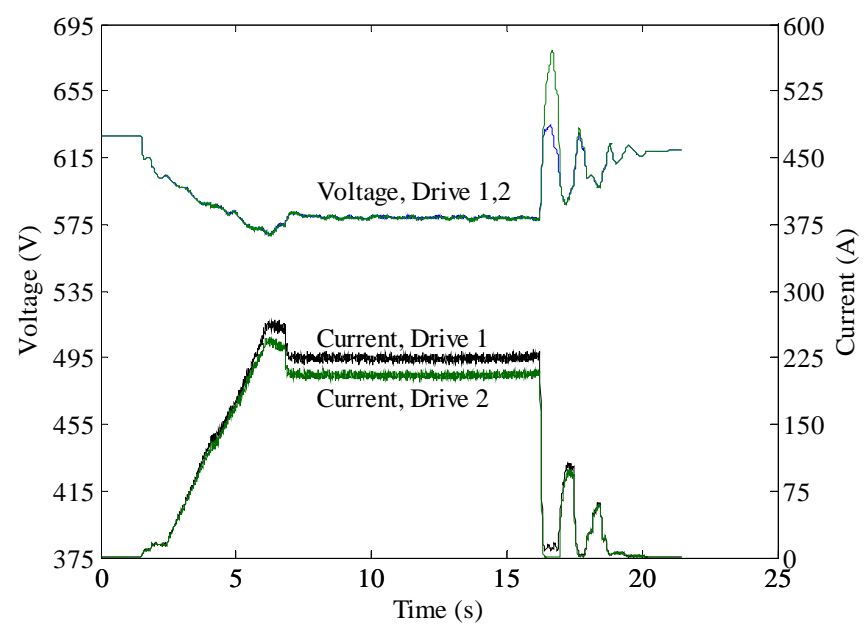

Figure 6. Dc bus voltage and rectifier current during container lift 
as more power is pulled from the alternator as expected. The drive voltages are nearly identical except for a brief time after the hoisting is concluded at approximately $16 \mathrm{~s}$. The voltages rise at the end of a lift because the drives employ regenerative braking to reduce the kinetic energy of the load at a controlled rate. The dc rectifier currents reflect the same mismatch as the drive powers discussed above.

\section{B. Lowering Event}

When the hoist is lowered, the conventional RTG crane has no ability to store the energy that is regenerated. This energy is thus dissipated as heat by the resistors shown in Fig. 2. Fig. 7 shows the dc bus voltage of drive 1 and the filtered dc bus power regenerated from both motor drives during the lowering of the empty spreader. The waveforms are similar for the case when the container is lowered. During the constant power portion of the waveforms, the hoist is lowered at a constant speed. To stop the descent of the hoist, power regeneration from the motor drives is increased thereby extracting the kinetic energy from the spreader as can be observed during the interval from 16 to $18.5 \mathrm{~s}$. Note that while the hoist is being lowered and the resistor is dissipating power, the voltage oscillates between 730 to $750 \mathrm{~V}$ as the chopper switches the resistor into and out of the circuit. Additionally, the motor drive power mismatch during lowering is reversed compared to the lifting case.

\section{RTG Crane Efficiency}

By comparing Figs. 4 and 7, an aggregate efficiency estimate can be computed for the crane hoist system including: the crane's mechanical hoisting components, the hoist motor, and the inverters of the hoist motor drives. Specifically, from Fig. 4 it is observed that an average total power of $113 \mathrm{~kW}$ was required to lift the empty spreader at a constant speed of $0.86 \mathrm{~m} / \mathrm{s}$. The total power received during regeneration when the hoist was lowered at the same speed was $61 \mathrm{~kW}$. The efficiency estimate, $\eta$, can then be calculated as

$$
\begin{gathered}
\eta_{t w o-w a y}=\frac{61 \mathrm{~kW}}{113 \mathrm{~kW}} \cdot 100 \%=53.9 \% \\
\eta_{\text {one-way }}=\sqrt{\eta_{\text {two-way }}}=73.5 \%
\end{gathered}
$$

\section{OVERVIEW OF FLYWHEEL AND MOTOR DRIVE}

The flywheel energy storage unit consists of a 3-phase permanent magnet synchronous motor-generator coupled to a steel flywheel on the same rotor. The rotor assembly is levitated on active magnetic bearings and spins in a vacuum to minimize losses. A 3-phase inverter functions as the flywheel's motor drive; the drive and flywheel motor are designed to transfer a maximum power of $150 \mathrm{~kW}$ to and from the dc bus. Energy storage is $4.57 \mathrm{MJ}(1.27 \mathrm{kWh})$ at a maximum speed of $36,000 \mathrm{r} / \mathrm{min}$. The mass of the unit is 320 $\mathrm{kg}$ yielding a specific energy of $14.2 \mathrm{~kJ} / \mathrm{kg}$. The flywheel unit is shown in Fig. 8 with a cutaway view of the rotor superimposed.

When flywheels are used with an RTG crane, two units are employed; a single unit provides isolated energy storage to an individual hoist motor drive as shown in Fig. 9. The two units are packaged together and installed underneath a crane support beam as shown in Figs. 10 and 11. Total energy storage with two flywheels is $9.14 \mathrm{MJ}$, which is much more than the 5.26 MJ of potential energy stored by a maximum hoist load of $50.6 \mathrm{t}$ as it traverses $10.6 \mathrm{~m}$. When a minimum operating speed of $10,000 \mathrm{r} / \mathrm{min}$ is taken into account, the total usable energy storage is $8.43 \mathrm{MJ}$.

The excess energy storage was reduced by decreasing the maximum operating speed to 20,000 r/min yielding a usable energy storage of $2.12 \mathrm{MJ}(0.59 \mathrm{kWh})$ for the flywheel pair. This decrease is advantageous as it results in decreased losses and simplified motor drive and magnetic bearing control. The final maximum operating speed was selected by considering the typical container masses most often encountered in operation and the efficiencies of the systems involved. For instance, typical containers mass $15 \mathrm{t}$, and relatively few mass more than $20 \mathrm{t}$. Thus the ability to capture the energy regenerated from lowering a $20 \mathrm{t}$ container is a desirable goal.

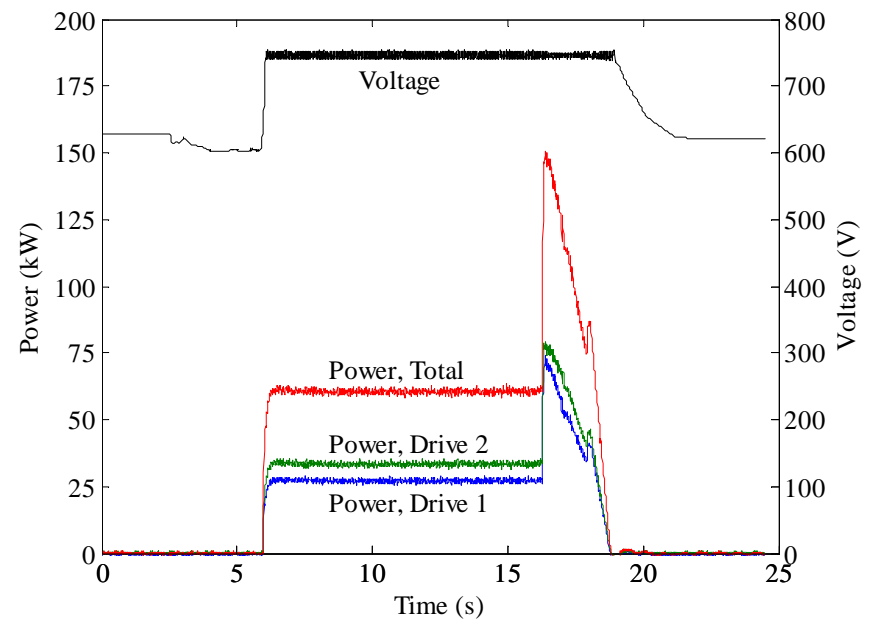

Figure 7. Motor drive power and voltage during lowering of spreader

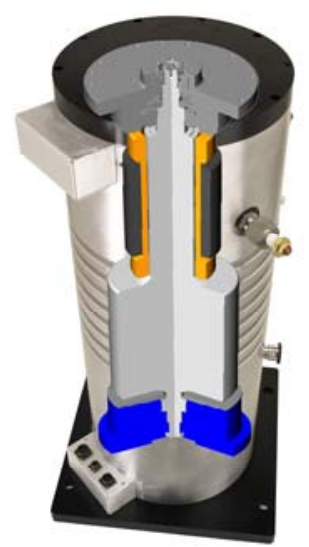

Figure 8. Flywheel unit with rotor superimposed 


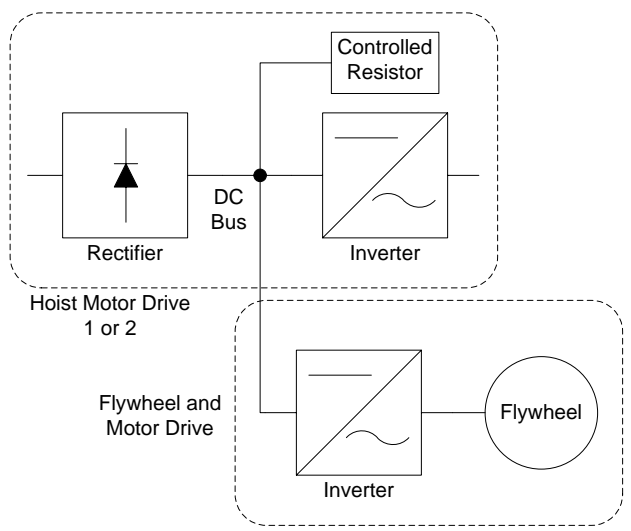

Figure 9. Flywheel interface to an individual dc bus

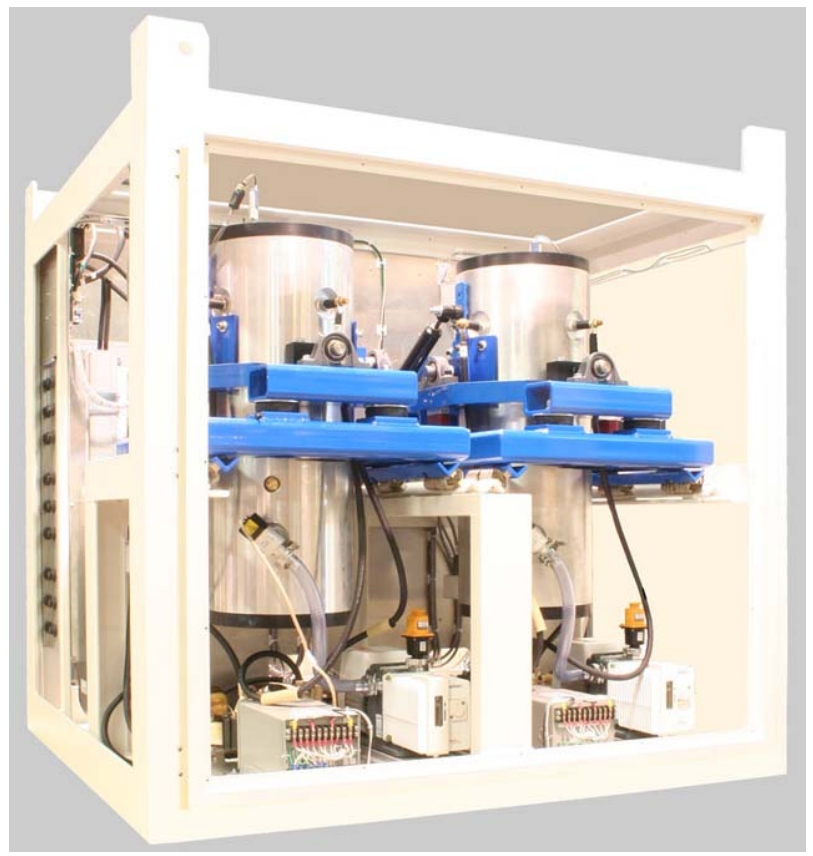

Figure 10. Two flywheel units arranged in a single package

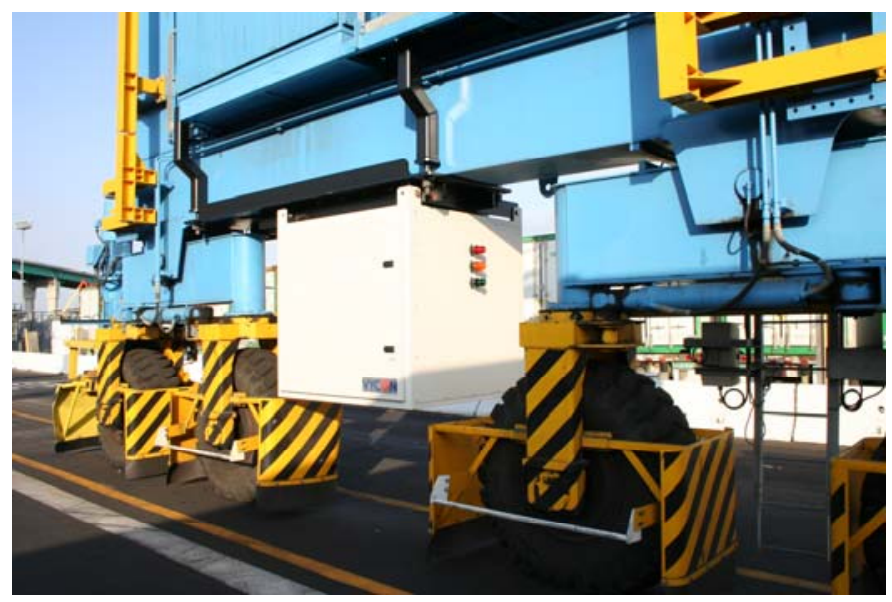

Figure 11. Flywheels installed on RTG crane
When lowered $10.6 \mathrm{~m}$, a $20 \mathrm{t}$ container (30 t including spreader) releases $3.12 \mathrm{MJ}$ which is more than the capacity of the flywheel pair. However, when the efficiency of the energy flow path from the container to the flywheel mass is included, the storage capacity is sufficient. For example, the efficiency of the crane from container to dc bus was computed in (2) as $73.5 \%$. The average one-way efficiency of the flywheel motor and its drive is $89.5 \%$. Using these two values the amount of energy that can be captured as a combined $30 \mathrm{t}$ spreader and container load descends $10.6 \mathrm{~m}$ is

$$
(3.12 \mathrm{MJ}) \cdot(0.735) \cdot(0.895)=2.05 \mathrm{MJ} \text {. }
$$

Other forms of energy storage for RTG cranes such as supercapacitors, have been reported in the literature [4]. However, compared to supercapacitors, high-speed flywheels can offer higher efficiency, higher cycle life without degredation, reduced ambient temperature concerns, and increased reliability owing to the absence of the hundreds of series connections in supercapacitor banks [5].

\section{CRANE Operation With FLyWhEELS}

\section{A. Initialization}

When an RTG crane is turned on at the beginning of a work shift, the diesel engine is started and allowed to warm up. The alternator is then connected to the hoist motor drives and the dc buses are energized. If the speed of an individual flywheel is below $10,000 \mathrm{r} / \mathrm{min}$, the respective unit is motored to this minimum operating limit where it remains until the first lowering event. If the speed of a flywheel is otherwise above $10,000 \mathrm{r} / \mathrm{min}$, it is allowed to coast at its present speed until the first lowering event described below.

\section{B. Lowering Event}

When not in service, the spreader is stowed at the maximum lift height. Thus, the first hoist operation performed by a crane operator is a lowering event of the empty spreader. The resultant voltage rise at each dc bus is used by the respective flywheel controllers to compute an appropriate power command for the flywheel motor drives to capture the regenerated energy. Fig. 12 shows the total power regenerated by the hoist motor drives to the dc bus as the spreader is lowered. The speeds of both flywheels increase during this time as the potential and kinetic energy of the spreader is absorbed. The mismatch in flywheel speeds reflects the power mismatch of the hoist motor drives and is of no concern during operation.

Fig. 13 shows the total regenerated dc bus power and flywheel speeds for when the $15.3 \mathrm{t}$ container is lowered. If the container is more massive than $20 \mathrm{t}$, the flywheels will be fully charged to $20,000 \mathrm{r} / \mathrm{min}$ before the hoist descent is completed. In this event excess power will be dissipated by the chopper controlled resistors. 


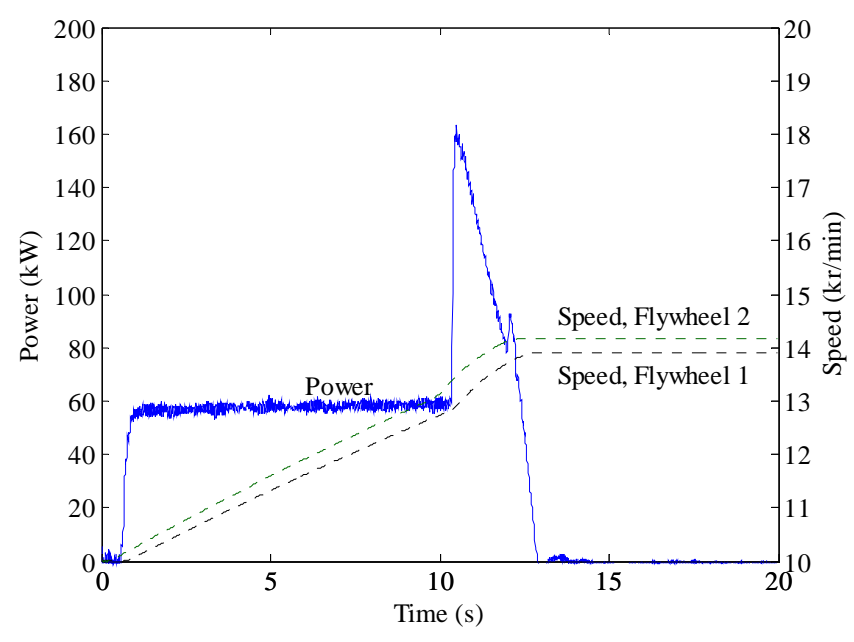

Figure 12. Regeneration during lowering of spreader with flywheels

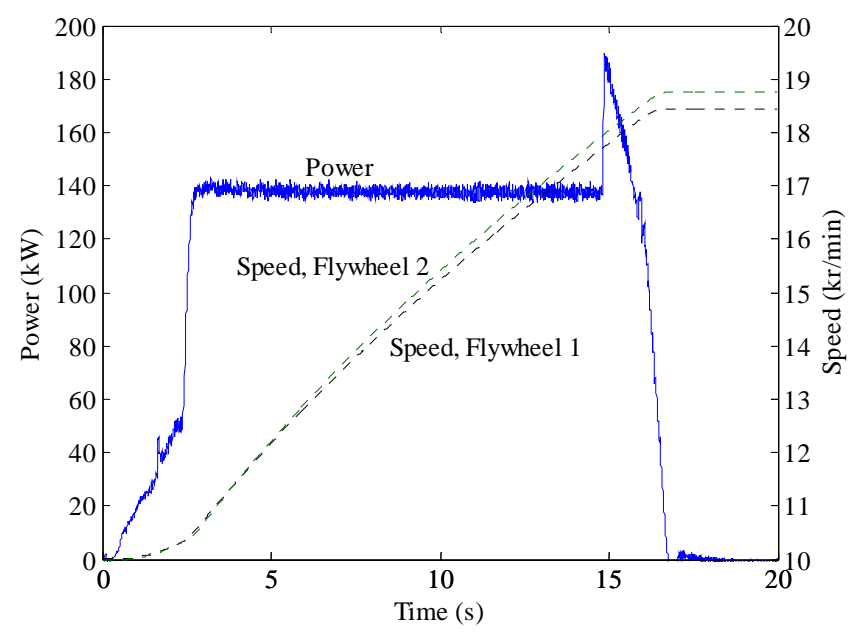

Figure 13. Regeneration during lowering of container with flywheels

\section{Lifting Event}

Energy stored in the flywheels during a lowering event is available for reuse during a subsequent lift. Figs. 14 and 16 show the hoist power provided by the diesel engine and the flywheel units during the lift of an empty spreader and a $15.3 \mathrm{t}$ container. The corresponding flywheel speeds are provided in Figs. 15 and 17.

During a lift, the flywheel controller measures the engine power at the dc bus and is programmed to limit the engine power to $50 \mathrm{~kW}$ by supplying the power difference required by the hoist while it is accelerating. In this manner, the peak power demand on the diesel engine is reduced which in turn reduces engine wear, fuel consumption, and emissions output. After the power peak, the hoist is lifted at a constant speed. The flywheel controller then gently reduces the maximum flywheel output power to $60 \mathrm{~kW}$ per flywheel unit $(120 \mathrm{~kW}$ per flywheel pair) allowing the engine to ramp up in power gradually and thus avoid heavy particulate emissions.

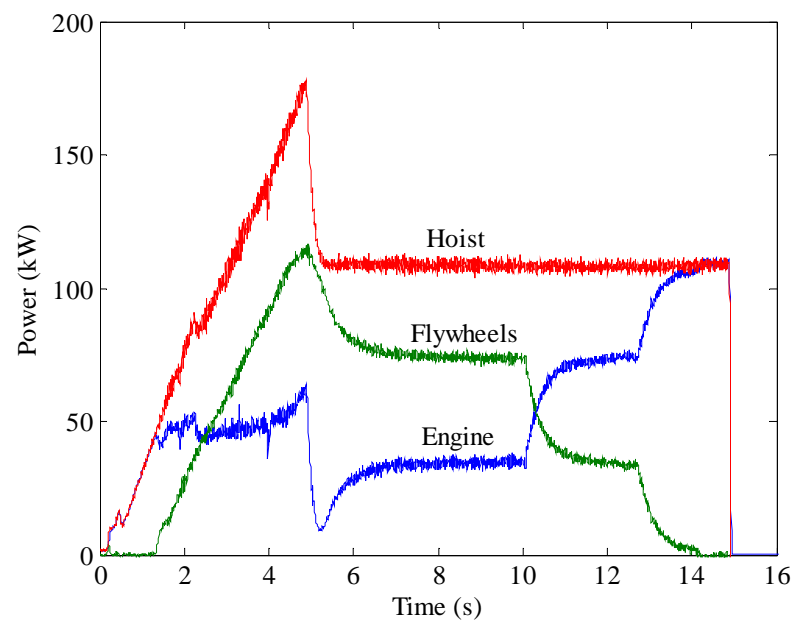

Figure 14. Dc bus powers during spreader lift with flywheels

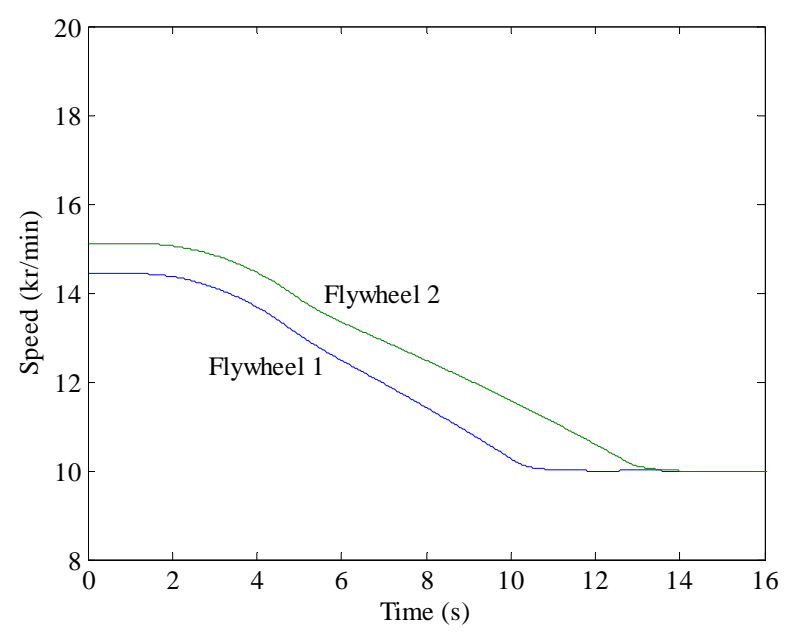

Figure 15. Flywheel speeds during spreader lift

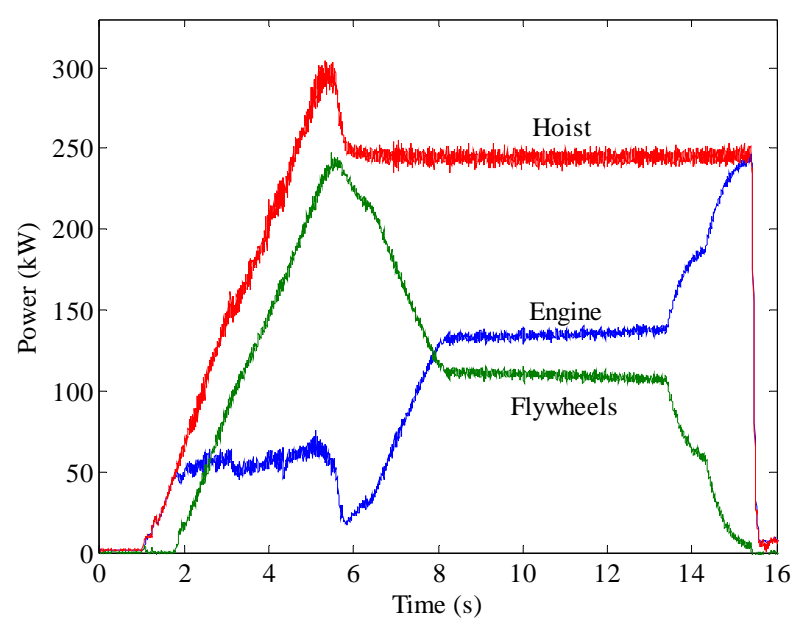

Figure 16. Dc bus powers during container lift with flywheels 


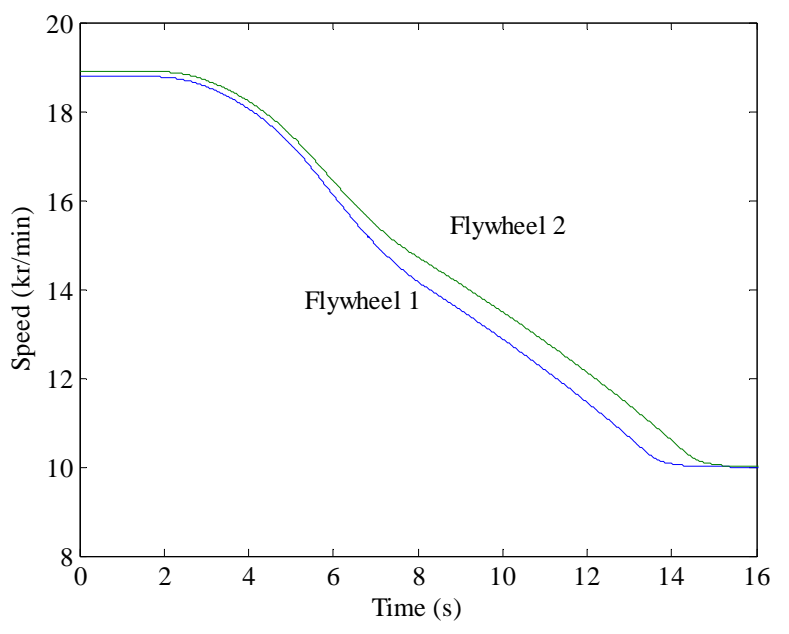

Figure 17. Flywheel speeds during container lift

As the flywheels approach a fully discharged state of 10,000 r/min, Figs. 14 and 16 show the remaining hoist power demand is transitioned to the engine gradually. Due to the power mismatch between the hoist motor drives, the flywheels are likely not to reach $10,000 \mathrm{r} / \mathrm{min}$ at the same instant. Therefore the power transition can be observed as occurring in two steps as each flywheel is discharged.

\section{Testing Results Summary}

Table II summarizes the fuel and emissions testing results during the one hour testing described above for the cases with and without the flywheel energy storage. Significant improvements were made among all quantities measured. Future enhancements to the flywheel energy storage are expected to yield further improvements.
TABLE II

FUEL AND EMISSIONS RESULTS WITH AND WITHOUT FLYWHEELS DURING ONE HOUR TEST

\begin{tabular}{cccc} 
& $\begin{array}{c}\text { No } \\
\text { Flywheels }\end{array}$ & $\begin{array}{c}\text { With } \\
\text { Flywheels }\end{array}$ & $\begin{array}{c}\text { Percent } \\
\text { Reduction }\end{array}$ \\
\hline Fuel Consumption (l/h) & 25.4 & 20.1 & 20.9 \\
Nitrous Oxides $(\mathrm{kg} / \mathrm{h})$ & 0.386 & 0.286 & 25.9 \\
Particulate Emissions $(\mathrm{kg} / \mathrm{h})$ & 0.0408 & 0.0136 & 66.7
\end{tabular}

\section{CONCLUSION}

The flywheel system has shown through experimental testing to greatly reduce fuel consumption and emissions output. Additionally, reduced peak power demand from the diesel engine increases engine life. Furthermore, due to the energy storage made available by the flywheels, the diesel engine can be reduced in size for greater fuel and emissions savings. As an added measure of reliability, were a single flywheel system to become inoperable, the crane can continue operating with the remaining flywheel. If desired, this lone flywheel can be configured to perform at elevated power levels for a limited time until service can be completed.

\section{REFERENCES}

[1] L.A., Long Beach Ports Produce Plan to Reduce Diesel Emissions Janet Wilson; Los Angeles Times; Jun 29, 2006; B.1;

[2] M. M. Flynn, J. J. Zierer, R. C. Thompson, "Performance Testing of a Vehicular Flywheel Energy System,” SAE 2005 Transactions Journal of Passenger Cars - Mechanical Systems, March 2006.

[3] G. Reiner, "Current State in the Application of Magnetodynamic (Flywheel-) Storage Systems in Urban Transport Buses,” presented at the Flywheel Storage Technology Workshop, Oak Ridge, TN, 1995.

[4] S. Kim, S. Sul, "Control of Rubber Tyred Gantry Crane with Energy Storage Based on Supercapacitor Bank," IEEE 36 ${ }^{\text {th }}$ Conference on Power Electronics Specialists,” June 12, 2005.

[5] S.R. Holm, H. Polinder, J.A. Ferreira, P. van Gelder, R. Dill, “A comparison of energy storage technologies as energy buffer in renewable energy sources with respect to power capability," IEEE Young Researchers Symposium in Electrical Power Engineering, Piscataway, NJ, 2002. 